\title{
Leave no one behind: The contribution of adult learning and education
}

\section{Paul Stanistreet ${ }^{1}$}

Published online: 20 August 2019

(c) UNESCO Institute for Lifelong Learning and Springer Nature B.V. 2019

This is an important moment for adult learning and education. At the start of July 2019, UNESCO published a report indicating that the world is significantly off-track in achieving the global development goal on education. ${ }^{1}$ Its projections show that without a significant renewal of commitment over the coming decade, the countries of the world will fail to achieve Sustainable Development Goal 4, which enjoins Member States to "Ensure inclusive and equitable quality education and promote lifelong learning opportunities for all". On current trends, one in six children will still be excluded from school by 2030 , while 30 per cent of adults and 20 per cent of young people in low-income countries are projected still to be unable to read.

This makes for depressing reading. The interconnected nature of the 17 Sustainable Development Goals (SDGs) ${ }^{2}$ means that our failure to make progress against the goal on education and lifelong learning has a serious knock-on effect for the goals on, for example, gender equality, climate change, poverty and health, and indeed for the prospects of the 2030 Agenda for Sustainable Development as a whole. The good news is that there is still time to get the world back on track. Less positively, the signs are that participation in education, and in adult education in particular, remains patchy at best, and that opportunity to learn continues to coalesce around the most advantaged and those who have already benefitted the most from education (the so-called "Matthew effect" discussed in our opening article by Silke SchreiberBarsch and Werner Mauch). The international community's commitment to "leave no one behind" in pursuit of sustainable development is looking increasingly difficult to realise.

\footnotetext{
1 UNESCO (2019). Meeting commitments: Are countries on track to achieve SDG 4? Paris: United Nations Educational, Scientific and Cultural Organization. Retrieved 5 August 2019 from https://unesd oc.unesco.org/ark:/48223/pf0000369009?posInSet=1\&queryId=06c83816-e565-4784-ba6d-4166b0d9a1 01.

${ }^{2}$ UN (2015). Sustainable Development Goals knowledge platform [online resource]. Retrieved 5 August 2019 from https://sustainabledevelopment.un.org/.
}

Paul Stanistreet

p.stanistreet@unesco.org

1 UNESCO Institute for Lifelong Learning, Hamburg, Germany 
Adult learning and education (ALE) has a rich - and exceptionally well-evidenced - potential contribution to make to supporting the achievement not only of SDG 4, but also of many of the other 16 Sustainable Development Goals. As the third Global Report on Adult Learning and Education demonstrated, adult education has a positive impact on health and well-being, employment and the labour market, and on social, civic and community life. ${ }^{3}$ It leads to improved health behaviours and attitudes, higher life expectancy and a reduction in lifestyle diseases, with a commensurate reduction in healthcare costs. It also has benefits for individuals in the labour market, for employers and for the economy more generally. Last but not least, it increases social cohesion, integration and inclusion, boosts social capital and improves participation in social, civic and community activities (ibid.).

The Sustainable Development Goals and the array of economic, social and environmental challenges we face globally are the starting point for Silke SchreiberBarsch and Werner Mauch's analysis of the potential role of ALE in responding to these challenges. In their article entitled "Adult learning and education as a response to global challenges: Fostering agents of social transformation", they recognise that ALE constitutes a "valuable and visionary" response to these challenges. However, they argue for an understanding of this as a "two-way" process, according to which

responding implies a necessary adaptation to the requirements of today's globalised societies as well as a critical reflection on these requirements and on fostering the potential of ALE to open up alternative pathways and frameworks beyond standard or dominant agendas, discourses or practices.

This is an important acknowledgement, which points also to a tension at the heart of adult education. As the authors note, adult education has always "oscillated between two poles: adaptation on the one hand and empowerment to social transformation on the other". In the spirit of critical reflection, the article examines UNESCO's guiding frameworks for social transformation and provides a critique of indicators, monitoring exercises and needs-assessment procedures. It also stresses adult education's important link to social struggle and citizenship and its mandate in not only raising but also hearing voices as part of a partnership dialogue conducted on equal terms. This implies a recognition of ALE as an open-ended process, the outcomes of which are frequently uncertain and hard to predict.

The article goes on to explore the relationship between ALE and sustainability, arguing for an understanding of ALE as sustainability, corresponding to the emancipatory, participative and open-ended understanding of adult education (as opposed to the more instrumentalist approach of education for sustainability). The authors contend that ALE can be understood as a driver of change, with local communities acting as "suitable terrain to connect the global and the local". While ALE cannot be the only solution to global challenges, it may "provide fertile ground from which change can grow, which in turn fertilises the soil of a viable world". Resisting the

\footnotetext{
3 UIL (UNESCO Institute for Lifelong Learning) (2016). The impact of adult learning and education on health and well-being; employment and the labour market; and social, civic and community life. Third Global Report on Adult Learning and Education. Hamburg: UIL.
} 
top-down policy model, the authors make a case for their two-way model, based on "partnership dialogue on equal terms at all levels" and implying "the possibility of resistance to policy": a "genuine dialogue", in other words, with all the potential awkwardness and uncertainty that implies.

The participative understanding of adult education defended by Schreiber-Barsch and Mauch can be traced back to the human rights-based approach of ALE that emerged with the creation of UNESCO (though its roots can be traced back much further) and that has resurfaced at intervals since - most recently in the context of the 2030 Agenda for Sustainable Development and its statement of the centrality of lifelong learning. ${ }^{4}$ This is the perspective explored by Maren Elfert in her article "Lifelong learning in Sustainable Development Goal 4: What does it mean for UNESCO's rights-based approach to adult learning and education?" She argues that while the inclusion of "lifelong learning" among the development priorities of the international community is significant and encouraging from the perspective of adult education advocacy, there is "cause for scepticism that ALE, in particular human rights-based ALE, will receive more attention under the SDGs" than it did before.

Elfert's article surveys the emergence and development of the rights-based, citizenship-oriented approach to adult education often associated with UNESCO and, in particular, with two seminal reports, Learning to be (the so-called Faure Report) ${ }^{5}$ and Learning: The Treasure Within (better known as the Delors Report). ${ }^{6}$ These reports have exercised significant influence on the work and thinking of adult educators, but their impact on the direction of education policy, whether at national or international level, has been, by comparison, negligible. While "lifelong learning" and "adult education" have enjoyed transitory star status among policymakers, with lifelong learning in particular now firmly part of global education discourse, these concepts are understood almost exclusively in terms of narrowly defined economistic outcomes (enhanced employability, skills development, economic growth, and so on) and individualistic benefits (better jobs, career development, increased income, etc.). The radical potential of the Faure and Delors reports, with their promise to transform wider society, as well as the economy, has not been translated into policy, while UNESCO's focus, up until 2015 and the launch of the SDGs, drifted away from ALE and lifelong learning.

But what does the relative prominence given to lifelong learning in the SDGs mean for adult education? Elfert argues that we are unlikely to see much change. The overwhelming focus on schools and higher education in SDG 4 and the global Education 2030 Agenda, reflected in major international policy statements and initiatives, coupled with the under-funding of adult education and neglect of

\footnotetext{
${ }^{4}$ UN (2015). Transforming our world: The 2030 Agenda for Sustainable Development. A/RES/70/1. NewYork: United Nations. Retrieved 5 August 2019 from https://www.un.org/en/development/desa/ population/migration/generalassembly/docs/globalcompact/A_RES_70_1_E.pdf.

5 Faure, E., Herrera, F., Kaddoura, A.R., Lopes, H., Petrovsky, A.V., Rahnema, M. \& Ward, F.C. (1972). Learning to be: The world of education today and tomorrow. Paris: UNESCO/Harrap. Retrieved 5 August 2019 from https://unesdoc.unesco.org/ark:/48223/pf0000001801.

${ }^{6}$ Delors, J., et al. (1996). Learning: The treasure within. Report to UNESCO of the International Commission on Education for the Twenty-first Century. Paris: UNESCO.
} 
marginalised groups, suggest that ALE will remain a low priority, both internationally and at country level. Informal and non-formal learning, she writes, "are associated with social movements, grassroots community-organising and collective activity that have been largely dismissed in favour of an approach in which learning is constructed as an individual and personal issue". Without a "transformative vision", Elfert concludes, the referencing of human rights in the SDGs is "little more than a token to make it more acceptable to civil society". Perhaps the lack of progress against SDG 4 will prompt a reappraisal. As Elfert writes, in broad agreement with Schreiber-Barsch and Mauch, a human rights-based approach to adult education has much to contribute to "transforming our world" and addressing global challenges such as climate change. It remains to be seen whether nation states and the international community are able to deliver the step change required to give substance to their commitments on ALE and lifelong learning.

Addressing challenges such as climate change and sustainability means, among other things, taking non-Eurocentric approaches to education and learning seriously. This has been something of a blind spot in thinking about education, both in the Global North and within the international community, dominated, as it still is, by Western European perspectives generally inimical to different paradigms for education that are culturally grounded and have developed in a way sympathetic to the needs of their respective societies. One such paradigm, explored by Ly Thi Tran and Tony Wall, is ubuntu. In their article, "Ubuntu in adult vocational education: Theoretical discussion and implications for teaching international students", Tran and Wall introduce the educational philosophy of ubuntu, which they describe as "an African worldview prioritising 'humanness' and interconnectedness". They use this approach as a "conceptual lens" through which to analyse pedagogical practices in teaching international students. Previous studies suggest that international students often feel forced to adapt to Eurocentric expectations of teaching and learning. Responding to other scholars' calls for education to be reconceptualised using alternative paradigms, the authors consider the teaching and learning of international students in the context of vocational education, arguing that ubuntu can challenge conventional pedagogical practices in the field.

Drawing on research conducted in Australia that examined teachers' adaptation of pedagogical practices in accommodating international students in the vocational education sector, Tran and Wall highlight three main ways in which the ubuntu approach can improve the practice of teaching international students - humanness, interconnectedness and situatedness - while challenging conventional ways of viewing international students as the "other" in "our" education system. Embracing ubuntu "with its humanistic ethos and emphasis on interconnectedness" allows international education to move beyond current practice, they argue, bringing to the fore pedagogies that take into account the human needs of students and which create a "sense of interconnectedness among all members of the learning and social community". As the authors hint, this study could have wider applicability to different forms of adult education and learning, and it is certainly to be hoped that it prompts further research into the possibilities and challenges of adopting ubuntu-inspired educational approaches across different education sectors. 
One of the challenges of lifelong learning planning and policymaking is to support learning among adults and young people in rural communities. "New Professional Farmers' Training (NPFT): A multivariate analysis of farmers' participation in lifelong learning in Shaanxi, China", by Dan Zhao, Yuchun Chen, Bruno Parolin and Xiao Fan, focuses on the participation of farmers in professional training in China. The authors show how urbanisation has prompted rural-urban migration with a resultant loss of agricultural land, a shortage of rural labour and a lowering of agricultural productivity - all factors hindering the development of modern agriculture in the country. As a result, there is increasing pressure on the education sector to produce modern professional farmers who understand and are able to implement the latest techniques in agricultural management. This important study considers farmers' willingness to participate in "new professional farmers' training", exploring individual characteristics, economic capital, educational opportunity and technological perception. It concludes that age, size of farm, total annual household income and training experience are all relevant factors, arguing that the training programme could be improved through greater attention to the needs of agricultural workers, increasing capital investment, establishing a diversified investment system and mobilising the enthusiasm of rural labourers. These findings will, I suspect, chime with the experience of adult educators that promoting participation in learning is about much more than simply creating an opportunity: adult learners need also to feel engaged in their subject, to see its relevance to their changing needs and to have some degree of agency and ownership over how and what they study.

One of the characteristics of distance education, as explored by Dimitrios Vlachopoulos and Agoritsa Makri in their article "Online communication in distance higher education: A framework of good practice", is the exceptional degree of autonomy and flexibility afforded to learners. However, a lack of tutor presence and peer support can mean that distance education is also an isolating and lonely experience, which can have a negative impact on course attainment and retention. Vlachopoulos and Makri reflect on how online communication and interaction can mitigate these factors in distance higher education, exploring good practice in the field and highlighting strategies for the improvement of online learning environments. It is important that such strategies are understood and factored into the design of distance learning courses if online learning is to achieve its much-touted potential and distance education students are to get the most out of the educational opportunities presented by new and emerging technologies. The authors argue that improving interaction between student and tutor, among students and between students and their course content could have a significant positive impact on distance learning course outcomes.

The final article in this issue considers a related issue: the importance of selfdirected learning and how it can best be fostered among students. In "Self-directed learning: A fundamental competence in a rapidly changing world", Thomas Howard Morris describes self-directed learning as fundamental "for working and living in our modern world", particularly given the context of rapidly changing digital technology. His article reviews the historical foundations of self-directed learning, considers who may benefit, explores the factors that influence the likelihood of self-directed learning, and examines existing research on the outcomes of 
self-directed learning. The studies Morris considers indicate the mixed quality of self-directed learning outcomes in formal education. Where learners do not progress satisfactorily, there is a danger that programmes may revert to more traditional teacher-directed models, he argues, thus obviating the anticipated benefits of learner empowerment and increased agency and adaptability. This is an important conclusion. Strengthening adults' capacities to direct their own learning is - or should be - an important dimension of nation states' efforts to create multiple learning spaces and develop more flexible pathways between formal and non-formal learning and between learning and work: both are critical undertakings in getting the world back on track to achieve Sustainable Development Goal 4.

As Schreiber-Barsch and Mauch argue, adult education is about not only adaptation but also "empowerment to social transformation". This view is in broad agreement with UNESCO's humanistic vision of lifelong learning, as described by Faure and Delors, but it is in sharp contrast to the prevailing instrumentalism of policy among Member States, which prioritises basic skills and employment outcomes at the expense of a rounder appreciation of human potential. This approach has been found wanting. The nature of modern work and life is such that it is no longer enough simply to prepare individuals for a job. We need instead to equip people for a life in which they will fulfil many different roles and undertake different kinds of work, developing their capacities accordingly, throughout and across their lives. We need good workers, but we also need good citizens, good parents, friends and lovers, and good leaders able to effect positive change in the lives of their families and communities. The challenges of the future, encapsulated in the 17 Sustainable Development Goals, require citizens who are resilient, creative, adaptable and, perhaps above all, willing and able to learn.

Permit me to conclude on a personal note. It is a huge privilege to write my first introduction as Executive Editor of the International Review of Education - Journal of Lifelong Learning (IRE). I would like to take the opportunity to express my appreciation of the other members of the Editorial Team, Maya Kiesselbach and Roselyne Höner, who have been unfailingly helpful and supportive during my first three months as Editor. They have been for many years, and remain, the mainstay of this publication. I would also like to acknowledge the outstanding work of my predecessor, Stephen Roche. Stephen did a tremendous job as editor, strengthening IRE's reputation over the past seven years and successfully overseeing its shift in focus to lifelong learning. He has been generous in his support and advice during this transitional period and has demonstrated great professionalism in helping to ensure the journal continues to maintain the excellent progress made under his stewardship. I am grateful to him.

Publisher's Note Springer Nature remains neutral with regard to jurisdictional claims in published maps and institutional affiliations. 